\title{
A Handbook on the Management of Acoustic Issues During the Building Process
}

\author{
Klas G. Hagberg ${ }^{1}$ and Christian Simmons ${ }^{2}$ \\ ${ }^{1}$ AF Sound \& Vibration, Box 1551, SE-401 51 Göteborg, Sweden \\ klas.hagberg@afconsult.com \\ ${ }^{2}$ Simmons akustik \& utveckling AB/Luleå Univ. of Technology, \\ Krokslätts Fabriker 1, SE - 43137 Mölndal, Sweden \\ christian.simmons@euromail.se
}

(Received 8 October 2009 and accepted 19 July 2010)

\begin{abstract}
A new handbook has been published by the Swedish National Board of Housing, Building and Planning. This handbook describes the building process from an acoustical point of view. It focuses on the conversion of functional requirements on the performance of the building to appropriate designs of a building. This type of requirement allows all kinds of solutions to be applied, but is also requires coordination of acoustic issues between the parties involved during the entire building process. Hence, the handbook addresses detailed information to each party. Functional requirements and acoustic issues are complex by nature, because they affect many building elements, they are handled by several parties and they must be considered during several phases of the building process. Typical errors come from building designs (floor plans), product designs (input data of elements), calculation models, quality of workmanship (during the construction phase) and uncertainties in field measurements. The aim is to help the commissioner manage the responsibility for these issues. The handbook also covers a large field of practical applications to support the acoustic expertise. It is expected that this handbook will encourage developers and contractors to deal with acoustic issues more efficiently. If the noise environment is not considered in the design process for new residential areas and other building facilities, the satisfaction of tenants, the health costs for the society and the building values will be affected. If verifications are made only at a late stage of the building process, errors are normally discovered too late. They are then expensive to correct for and it is difficult to find out who is responsible. When the verifications are made effectively during the process, costs are minimized.
\end{abstract}

\section{INTRODUCTION}

This paper summarizes the content of a new handbook, which includes; a description of the process to handle acoustical issues during the building process; practical advice to all parties involved in the process and interpretations of functional requirements in sound classifications standards that are referred to by the Swedish building regulations. However, this paper does not discuss scientific theory. The aim is rather to describe a 
practical way to deal with acoustics throughout the building process, from the interpretation of the functional requirements, the early stage design, the purchase of building elements to the finalized building.

The modern building process is complicated. For those who deal with acoustic issues in the design phase or the construction phase, this is obvious for several reasons. New buildings are often erected at complicated sites in the city centres. Hence, they are often exposed to high sound levels and ground vibrations from various types of traffic. High requirements on sound insulation between the interior spaces are frequent, e.g. between residential apartments and premises for public activities (shops, restaurants, theatres, cinemas etc) and these requirements tend to be raised further in future. Furthermore, new architecture and new building products are often suggested, which require a lot of knowledge to use since empirical experience is not always at hand for these specific solutions.

There is now a need to transfer acoustic knowledge directly to our building industry, since the teaching of building acoustics at our universities has been significantly reduced. It is too expensive to retain acoustic laboratories at the universities, since they are not efficiently used, hence converted and used for other purposes. Furthermore, the governmental grants to research and teaching have been reduced which has resulted in fewer civil engineers graduated with even basic knowledge in acoustics.

At the same time, modern buildings become more and more complicated, and the building acoustic demands from inhabitants and commercial developers are increasing. Lightweight structures (e.g. wood or steel) are being used more frequently in multi storey residential buildings, which present large challenges to the acousticians.

The possibility to use various building products is now easier than some decades ago, partly because the requirements are based on performance of the building (or spaces therein) instead of the properties of individual products. Performance based building codes may be regarded as an "open system" compared to codes based on specific dimensions and constructions.

However, an important disadvantage of a performance based building code is the need for conversion from the performance of products to the expected performance of buildings. Requirements on dimensions and constructions are more "straight forward" to apply and to verify by inspection in situ. However, the advent of EN 12354 [1] and extensive laboratory tests have helped the acousticians to make rational choices and decisions with respect to combinations of products, at least in those cases where the standardized calculation models are applicable. There are now an increasing number of innovative products and structural elements that might be combined in order to meet the requirements stated by the client or the national building codes.

Furthermore, the requirements are often changed. In Sweden (as well is in some other countries), the requirements by authorities or clients normally refer to the sound classification standards or similar publications. The Swedish standard SS 25267 [2] addresses requirements for dwellings and the SS 25268 [3] addresses spaces in hospitals, schools, offices, hotels and institutional premises. The idea behind a classification system is to offer the developer a choice of a level of acoustic quality (sound class) that is appropriate for the actual performance level considering the 
acceptable cost level. The sound class may vary in different projects, from renovation of old buildings (low sound class) to very high ambitions (luxury apartments).

Acoustic issues affect many building constructions, several parties must handle them and they influence several phases during the building process. Typical errors come from building design (floor plan), product design (data), calculation models, assemblies in the building (construction phase) and uncertainties in field measurements.

\subsection{A new handbook}

On the initiative of the National Board of Housing Building and Planning (Boverket), a new handbook has been issued, in an attempt to facilitate the management of building projects with respect to the acoustic issues. The handbook is written to meet the following needs:

- to describe how the commissioner (e.g. a developer or a proprietor) can specify the responsibility for different parties involved during the building process. Each party then gets specific targets to facilitate his handling of acoustic issues.

- to present interpretations and application examples on the Swedish sound classification standards, based on a large number of real questions and detailed examples from the building industry, universities and consultants.

- to complement other guidelines and advisory notes from the National Board of Housing Building and Planning used by local authorities.

The handbook consists of seven sections:

- Sections 1 and 2 address information to all participants in the building process who may come in contact with acoustic issues, for example proprietors, developers, authorities, designers, manufacturers, building contractors, experts, quality controllers etc. They give general background information and a description of which parties should take responsibility during each phase of the building process.

- Section 3 recommends the commissioner to engage an acoustic expert to monitor all phases of design, drawings, building details at the site, as well as the verification measurements in partly finalized or in the finalized building. As a result, the acoustic documentation is assembled. This documentation is a living document that may support the other parties of the project team during the building process.

- Section 4 is primarily addressed to experts within acoustics, involving detailed advices on risks and interpretation aspects on the sound requirements.

- Section 5 gives information to manufacturers on how they should test and present the acoustical technical properties of their products, as well as supplementary information on how to ensure that the product fits to connecting structures, handling issues, mounting advices etc.

- Section 6 gives general advice to building contractors. The advice addresses several aspects which should be considered to avoid raised costs due to poor workmanship and a lack of precision during the construction phase.

- Section 7 clarifies the most important tasks to verify the acoustic performance of the building. It has become clear that the international standards for sound testing 
at the sites (ISO 140-series) are not detailed enough. Uncertainty may be reduced with complementary instructions, e.g. to minimize arbitrary choices of measurement locations etc.

However, the handbook does not cover all conceivable acoustic problems, nor does it give a general review of theoretical acoustics. It is intended to facilitate the management and the probability to fulfil the intended sound class, and to clarify responsibilities to all parties involved in each stage. It does give reference to papers and books on theory etc. that may be of interest to some parties, e.g. manufacturers of service equipment or building elements.

It is a well known fact that if technical aspects, i.e. acoustics, are not considered at an early stage this might lead to raised costs in the end of the building project, as illustrated by the figure 1 .

Relation; cost - sound quality

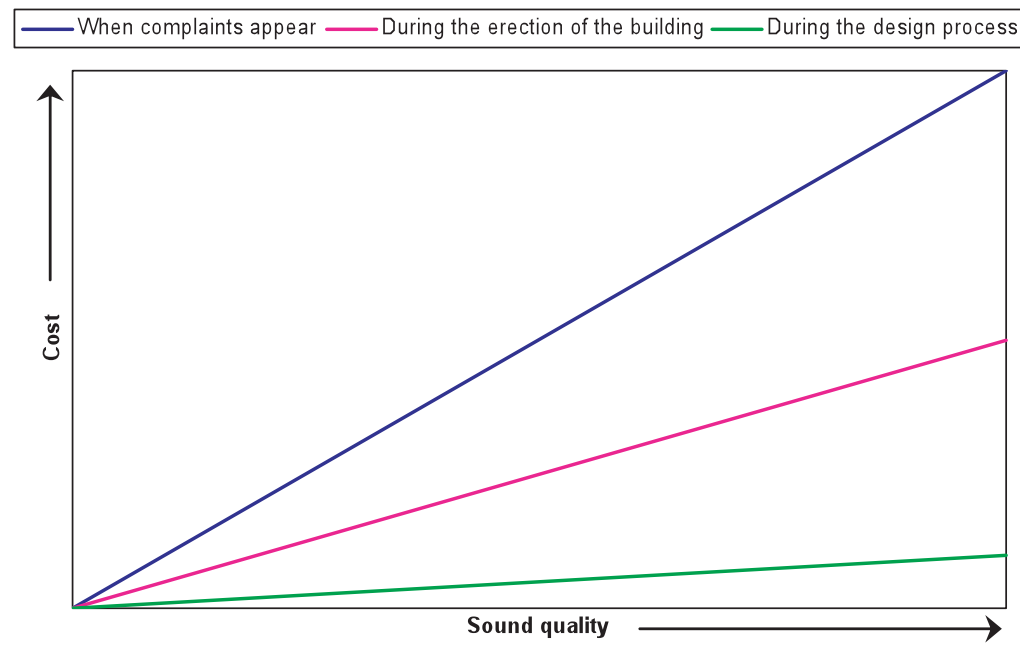

Figure 1. The relation between costs for acoustic (or other) measures and sound quality depending on when the technical issues are considered during the building process.

\section{THE COMPLEXITY OF THE BUILDING PROCESS}

There are often conceptual confusions within the building industry and between the parties of a project process, with respect to the variety of type of agreements, c.f. figure 2. In an attempt to simplify the process the purposes of different participants in the process are emphasized, no matter whom is responsible for a specific task at a specific time during the progress of a project. The handbook describes which parts should be managed and by whom: the developer, the experts, the designers, the manufacturers, the building contractors or the authorities. 


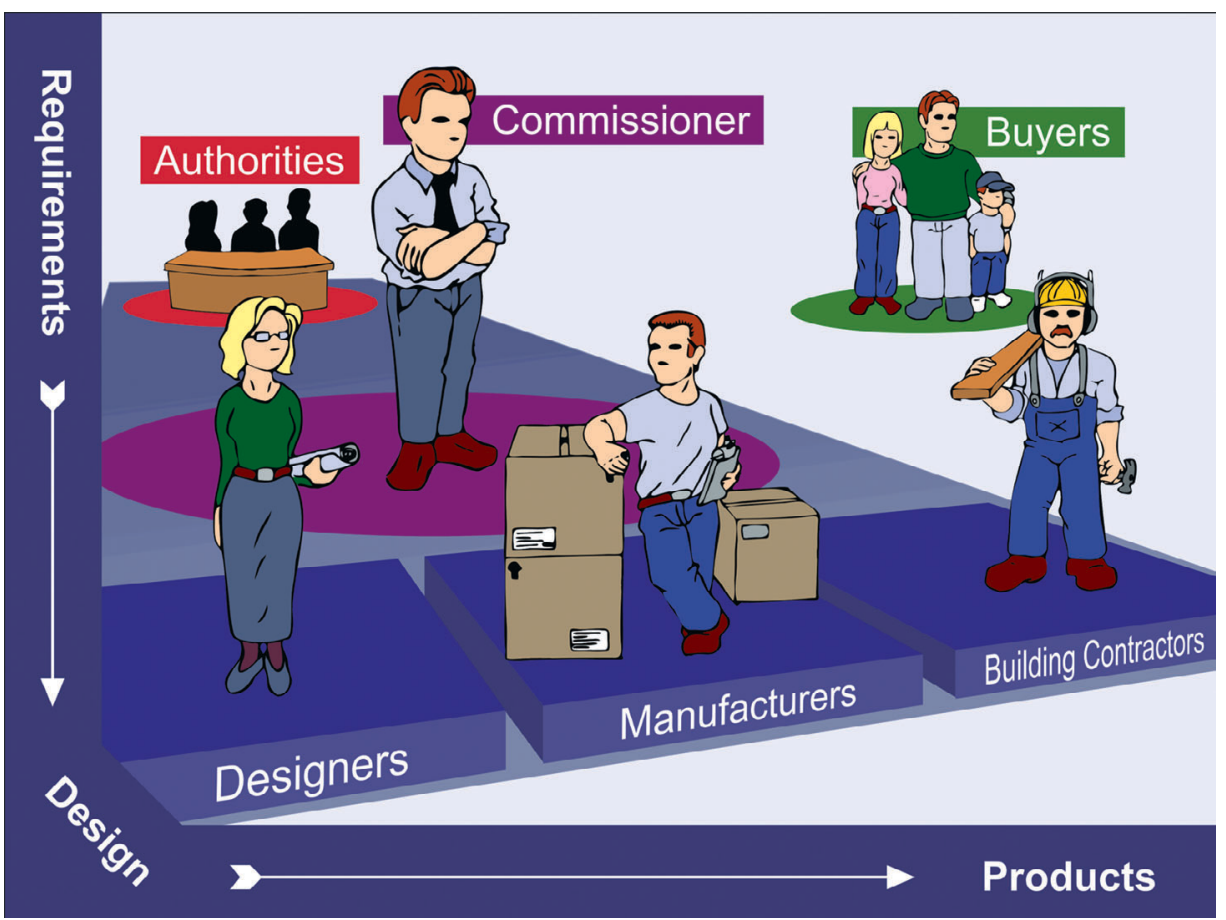

Figure 2. The complex matrix of actors involved in a building project. General performance based requirements (sound class) stated by the Authorities and the Developer must be interpreted by the Designer to constructions and to products. The Manufacturers must present correct input data to the Designer. The Contractor must follow all instructions carefully and handle risk constructions consciously. The final Buyer (or tenant) is often not involved at all during the planning, design and construction phases.

\section{THE STRUCTURE OF THE HANDBOOK}

\subsection{Acoustic documentation - created by the expert}

Frequently, there is no acoustician involved during the very early phases of a building process. They may be commissioned during the later stage of the design process or sometimes just to perform measurements in the finalized building or when a problem has occurred. However, the handbook advises the commissioner to engage an acoustician during all phases of the project. Then, all acoustical risks may be clarified and handled early, and all parties involved may be assisted by the acoustic documentation, updated throughout the process. Furthermore, an acoustic consultant knows where the acoustic efforts are most beneficial and may guide the client through the building process. The communication with the authorities is made easier by the assistance of an experienced acoustician.

The expert should establish an acoustic documentation with a structure described in section 3 of the handbook. In general the documentation may cover the following topics: 
- Part 1 specifies the sound requirements established by the developer (particularly if they deviate from the recommendations given by the sound classification standards). In this phase, the input data regarding exterior noise levels should be specified, as well as the façade elements (walls, doors and windows) that must attenuate noise from the exterior. In public premises, the requirements may be adapted to fit the needs of the current clients/tenants. In multi storey residential buildings, ralaxation of the requirements may be appropriate, for example on the impact sound insulation of staircases that are only intended for evacuation purposes.

- Part 2 contains recommendations for the design of the building (documented by drawings and product descriptions) such that it fulfils the current sound class (requirement). The risks should be highlighted, considering known issues with the actual structural elements (light weight or heavy structure, prefabricated or in-situ manufactured etc) as well as the specified building products.

- $\quad$ Part 3 describes the procedure for review and verification within different stages of the project.

\subsection{Other sections}

Section 4 is primarily addressed to designers and acousticians and it has the same basic structure as the Swedish sound classification standards. The content of section 4 gives background, interpretations and examples in order to increase the understanding and to facilitate the application of the standards. Its content is written on the basis of real questions and contains statements that reflect frequent attitudes by the building industry, universities, consultants etc. As an example, a developer is certainly free to pick single requirements from various acoustic properties in the different sound classes as long as the minimum national requirements are fulfilled. But the handbook explains why this is not recommended, i.e. it explains that the perceived sound level will be determined by the weakest part of the building. Hence, in some respects the building will be either worse or better than expected which is, of course, not cost efficient.

Section 5 describes current requirements, standards and methods applicable to manufacturers in order to deliver product data usable in the calculation standard series ISO EN 12354 (equal to ISO 15712) [1] which are of particular significance. The section also emphasizes the importance of good workmanship of field adapted assembly instructions, e.g. structures made of lightweight material.

Section 6 addresses building contractors and involves, amongst others, description of risk level, description of sensitive details, typical acoustical problems with regard to service equipments etc. Such descriptions are cumbersome to establish, because the variety of constructions and possible problems in intersections makes it virtually impossible to cover all risks that may occur. Hence, also the contractor must have some basic understanding of acoustics and be able to identify risks that have not yet been described.

\subsection{Verification}

Suitable verification procedures are necessary to produce a final building which 
actually meets the contracted sound class (or any requirement). Traditionally, acousticians are involved at a late stage performing measurements in the building. This is too late if something is wrong, see Figure 1. If involved very late, the acoustician's knowledge of the project is very limited which further complicates efficient measures. Undoubtedly, costs are minimized when the verification is carried out throughout the building process. As soon as decisions have been made or the work is already in progress, the verification should cover

- $\quad$ Requirement level, type of project contract, responsibility management

- Traffic density, type of traffic, sound pressure levels at the facade

- Structural framework, products in the building, final drawings

- Visits to the building site

- Measurements in the completed building

Depending on each project, its location, its form for contract, the choice of structural material etc the need for verification within each part above vary and should be stated in the acoustic documentation.

The intention of this part of the handbook is to clarify the need for surveillance carried out continuously throughout the process, and not solely relying on acoustical measurements. Continuous visual inspections during the construction phase and documentation of products which form a part of the building is important in order to take actions if something appears to be wrong - correcting measures may then be carried out immediately.

Furthermore, during the building process current basic prerequisites for the design have to be laid down. One such issue is to define the traffic conditions (traffic density, number of heavy vehicles etc) in order to choose the right windows and façade. The handbook also contains information on safety margins during design in order to manage the final requirements with sufficient probability, based on calculations which are compared to measurements presented in a Nordtest report NT Tec 603 [4] and a report from the Forum for building costs [5, 6].

\section{CONCLUSIONS}

There is a need for a shake-up regarding knowledge of aspects that cause acoustical problems in buildings. Every mistake not corrected as early as possible costs a lot of money and the final product quality may deteriorate more than necessary. A new Swedish handbook has been issued by our national authorities, to provide help to those who work in projects to secure the acoustical quality of buildings.

To promote acoustic knowledge directly to the building industry has become an even more important task during the last decade (or decades) since the teaching of building acoustics at the universities has been reduced. At the same time, modern buildings have become more and more complicated, and the building acoustic demands from inhabitants are increasing. Lightweight structures (e.g. by wood or steel) are increasingly being used in multi storey residential buildings, which present huge future challenges to the industry and to the acousticians.

The handbook is presently available in Swedish only. However, some countries have 
shown interest to translate the handbook into their language and of course it would be interesting to publish it in other languages, primarily into English.

\section{REFERENCES}

1. EN 12354 Building acoustics - Estimation of acoustic performance of building from the performance of elements. Parts 1-6. The parts 1-4 have been published by ISO without changes (ISO 15712 1-4)

2. SS 25267 Acoustics - Sound classification of spaces in buildings - Dwellings

3. SS 25268 Acoustics - Sound classification of spaces in buildings - Institutional premises, rooms for education, preschools and leisure-time centres, rooms for office work and hotels

4. NT Tech 603, Simmons C., "Reproducibility of measurements with ISO 140 and calculations with EN 12354.” ISSN: 0283-7234. Nordic Innovation Centre, Oslo (2005), www.nordicinnovation.net/nordtest.cfm.

5. National Board of Housing Building and Planning, "Bostäder och nya ljudkrav". ISBN: 978-91-85751

6. Hagberg K., Simmons C., "Consequences of new building regulations for modern apartment buildings in Sweden" Proceedings of INTER-NOISE 06, 2006. This paper gives is a brief summary of reference 5 . 